Revista de Filosofía y Teoría Política, n. ${ }^{\circ}$ 48, 2017, e012, ISSN 2314-2553

Universidad Nacional de La Plata.

Facultad de Humanidades y Ciencias de la Educación.

Departamento de Filosofía

\title{
Estilo literario y reflexión filosófica en el siglo XVIIl: Hume y Rousseau sobre el suicidio
}

\author{
Literary Style and Philosophical Reflection during the $18^{\text {th }}$ Century: \\ Hume and Rousseau on Suicide
}

\section{Valeria Schuster}

Universidad Nacional de Córdoba, Argentina | schvaleria@yahoo.com

\section{PALABRAS CLAVE \\ Hume \\ Rousseau \\ Suicido}

Estilo literario

Reflexión filosófica

KEYWORDS

Heraclitus

Descartes

DK 22 B3

Heraclitean skepticism

Heraclitean rationalism

\section{RESUMEN}

En el presente trabajo se realiza un estudio comparativo entre el ensayo Sobre el suicidio de Hume y las cartas XXI y XXII presentes en la tercera parte de Julia, o la nueva Eloísa de Rousseau, que fueron publicadas en conjunto por un editor anónimo en Inglaterra en 1783. Se analizan los argumentos presentes en cada uno de los textos, la disímil recepción que tuvieron por parte de los lectores de la época y las posibles fuentes compartidas. A partir de dicho estudio, se intenta mostrar cómo el estilo literario en el que están escritas estas obras, compartido por varios pensadores del siglo XVIII, se corresponde con la pretensión de generar un tipo de reflexión filosófica particular acorde con aquellos temas que no caen bajo el dominio de reglas generales.

\section{ABSTRACT}

This research focuses on the comparison of Hume's essay On Suicide and the letters XXI y XXII present in the third book of Julia or the New Heloise written by Rouseeau, that were published together by an anonymous editor in England in 1783. We will analyse the arguments present in both texts, the different reactions the audience of that time had and the possible common sources between them. On the basis of this study, the second attempt of this paper is to show how the literary style used in these works and common among the $18^{\text {th }}$ century thinkers is related to a particular kind of philosophical reflection upon issues that couldn't be measured by general rules. 
Cálmate. Desespera

por última vez. A nuestra especie el hado

sólo nos dio el morir. Ahora desprecia

a ti, natura, el indigno

poder que, oculto, en común daño impera,

y la infinita vanidad del todo.

A sí mismo

Giacomo Leopardi ${ }^{1}$

\section{Presentación ${ }^{2}$}

El problema de la muerte voluntaria estuvo presente durante el siglo XVIII en las reflexiones de distintos pensadores que, alejándose de una mirada estrictamente religiosa o jurídica del tema, se aventuraron a analizar un fenómeno tan particular como es el cese de la propia vida. Los dos escritos que nos proponemos examinar y poner en relación son Sobre el suicidio de David Hume y las cartas XXI y XXII de Julia, o la nueva Eloísa de Rousseau. Una de las características que comparten ambos textos es que están escritos en forma de diálogo; así, su estrategia de narración consiste en establecer un espacio de reflexión común entre el lector y el escritor, de manera tal que el discurso se presenta como compartido y plural. La nueva Eloísa es una de las tantas novelas epistolares que gozó de popularidad durante el siglo XVIII, perteneciente a un género que ganó rápidamente su espacio en la literatura ofreciendo relatos en los que se evidenciaban las particularidades psicológicas y sentimentales de los personajes. Sobre el suicidio, por su parte, es un ensayo -debido quizás al éxito editorial de los Ensayos Morales y Políticos - e incluye en sus líneas a dos interlocutores que intercambian pareceres y puntos de vista acerca de la muerte voluntaria. En nuestro estudio nos interesa indagar, entonces, por qué estos dos pensadores del llamado siglo de las luces eligieron para expresar sus reflexiones filosóficas un tipo de escritura tan particular como es el diálogo: cuál era su intención y propósito al optar por este estilo literario, cuál el efecto que pretendían provocar en el público lector. Y, partiendo del presupuesto metodológico que sostiene que ninguna obra es algo acabado y terminado en sí mismo, nos proponemos responder a estos interrogantes estudiando cuáles han sido las lecturas que han realizado dichos filósofos, y de qué manera han asimilado o criticado las fuentes a las que deben, en parte, su pensamiento y su forma de escritura. Así, la demarcación y el juego entre las categorías de literatura y filosofía quedarán, a los fines de este trabajo, planteados hacia el interior de lo que podemos llamar, en un sentido amplio, reflexión filosófica ${ }^{\underline{3}}$, entendida como una práctica cuya meta no consiste en distinguir claramente la ficción de la búsqueda de la verdad, sino más bien en problematizar sus similitudes y divergencias.

Asimismo, recuperar la lectura y el examen de obras como las que hemos elegido quizás sea de alguna utilidad con vistas a revisar cierta idea de la modernidad según la cual el interés filosófico de los pensadores de este período estuvo puesto, casi exclusivamente, en la tarea de fundamentar los conocimientos aportados por las nuevas ciencias y en encontrar juicios universales propios de la filosofía. Este es el diagnóstico que realiza Stephen Toulmin en el primer capítulo de su libro Cosmópolis. El trasfondo de la modernidad. De acuerdo con Toulmin, nos hemos formado una noción de modernidad, afianzada en los años 1930 y 1940, según la cual los autores de esa época 
tenían como único emblema la racionalidad: sus estudios estaban dedicados a la fundamentación de saberes científicos universales y eran llevados adelante con la convicción de que el progreso de las ciencias traería beneficios a todos los países civilizados. Estas inquietudes puramente epistemológicas se fueron materializando, luego, en un constante empeño en dominar y controlar la naturaleza. Dicha imagen de la época moderna, contra la cual luego se lanzan numerosas críticas, fue forjada, según el autor, en el siglo pasado, en particular en la segunda década del siglo XX (Cfr. Toulmin, 2001, pp. 27-50).. Como claro síntoma de esta noción un tanto distorsionada de la modernidad vemos, en relación con nuestra temática, que los escritos de Hume y Rousseau que quizás hayan gozado de mayor reconocimiento durante los últimos cien años son el Tratado de la Naturaleza Humana y el Contrato Social, respectivamente. En ambos escritos encontramos un mismo estilo narrativo: el Tratado -estandarte del iluminismo bajo la forma de la enciclopedia- en el cual se priorizan los juicios asertivos que se presentan (ya sea para fundamentar una Ciencia del hombre, por un lado, o para explicar el origen y el funcionamiento del gobierno, por el otro) de manera didáctica y con pretensiones de universalidad ${ }^{4}$. Recuperar el estudio de los textos propuestos (considerados muchas veces obras menores en el marco de la producción filosófica de estos pensadores) nos permitirá, entonces, ampliar y repensar las ideas acerca de la modernidad que perviven en nuestro tiempo.

Un último motivo por el cual puede ser interesante releer en la actualidad algunas meditaciones acerca de la muerte voluntaria propias del siglo XVIII es que quizás contengan alguna respuesta a una cuestión que en nuestros días ha sido absorbida, a nivel reflexivo, por el discurso científico. Las posibles causas del suicidio han sido investigadas por la sociología y la medicina (bajo la forma de la psiquiatría o la psicología) obteniendo como resultado ciertos parámetros bajo los cuales se produce, o se produciría, el fenómeno del suicidio; pero estas explicaciones no incluyen una valoración moral de la acción del suicida, ni pretenden reflexionar sobre su aprobación o condena. En otras palabras, quitarse la vida, desde el punto de vista del relato científico, ha dejado de ser una acción pecaminosa o moralmente reprochable, para pasar a ser un acto fruto de causas no voluntarias: el estado mental de la persona (bajo las formas de la depresión, la melancolía, la esquizofrenia, etc., interpretado cada vez más en clave fisiológica), o el estrato social y económico al que pertenece. Bajo esta mirada científica actual, el suicidio es desplazado del ámbito de las decisiones deliberadas de quien actúa para ser considerado, como las enfermedades físicas, el resultado de procesos irreflexivos; sin haber perdido por ello su valoración moral negativa, que se evidencia en la prohibición de la eutanasia o la muerte asistida. Los filósofos modernos de los que nos ocuparemos en este trabajo tenían puesto su interés, por el contrario, en pensar el suicidio como una acción que depende de la voluntad de quien la realiza y, por lo tanto, como objeto de un juicio moral. Dicho tratamiento es claramente filosófico y consiste en responder a una pregunta simple y básica, que carece de una respuesta única: el fin de nuestra vida, ¿está en nuestras manos o debe quedar librado a la naturaleza, el destino, la providencia, el Estado o algún otro principio ajeno a nuestra decisión personal? Detenernos en estas reflexiones quizás permita iluminar el problema de la muerte voluntaria desde una óptica no siempre presente en el discurso actual.

\section{Las obras en su contexto de escritura y publicación}

David Hume no publicó en vida el ensayo Sobre el suicidio ni dejó indicaciones para que se lo 
hiciera de manera póstuma, tal como sí ocurrió con los Diálogos sobre la religión natural. De todas maneras, sabemos que una copia de este texto circuló, sin el nombre de su autor, a partir de una prueba de impresión realizada por su editor en 1756 de la cual luego Hume retiraría este ensayo debido al revuelo que causó entre quienes lo leyeron (Cfr. Mossner, 1950, pp. 37-57). Recién en 1783 un editor anónimo llevó a la imprenta Sobre el suicidio y Sobre la inmortalidad del alma, reconociendo la autoría de Hume, e incluyó en el volumen una serie de notas para alivianar el veneno contenido en sus páginas junto a dos fragmentos de la novela Julia, o la nueva Eloísa de Rousseau. Esta versión anotada por el editor fue la más difundida en Inglaterra en las últimas décadas del siglo XVIII, apareciendo nuevamente en 1789 y en 1799. A diferencia del escrito de Hume, la Nueva Eloísa tuvo un éxito extraordinario desde el momento de su publicación $\underline{5}$ y fue recibida con entusiasmo por los lectores de la época que no se escandalizaron con las cartas XXI y XXII --de la tercera parte-, en las cuales Rousseau trata el tema de la muerte voluntaria. Pero, curiosamente, y a pesar de su recepción tan disímil por parte del público, el tratamiento del tema que encontramos en Sobre el suicidio, lejos de disentir, coincide en lo fundamental con el punto de vista moral expresado en las Cartas entre dos amantes de Rousseau. Tomando como punto inicial de nuestra indagación la publicación conjunta de estos trabajos en 1783, comenzaremos por intentar determinar por qué la opinión de los lectores fue tan diferente en Francia y en Inglaterra al conocer estas obras, para luego pasar a analizar los argumentos que se presentan en cada una de ellas.

Rousseau empezó a escribir Julia en 1757 en su estancia en el Ermitage, donde encontró el descanso que le permitió alejarse de la agitada vida de París. Ocupado durante ese período en la tarea de copista, también se dedicaba a escribir guiado por la siguiente convicción: "siempre he creído que la condición de autor no podía ser ilustre y respetable sino estando lejos de ser un oficio. Es harto difícil pensar noblemente, cuando se hace para vivir.” (Rousseau, 1948, p. 368). Junto con esta máxima, que sostuvo toda su vida, fueron apareciendo las primeras líneas de su novela epistolar. Así, aislado de la ciudad y viviendo en un medio natural, el filósofo encontró en su propia imaginación un alivio y un feliz escape del trato humano; dicho con sus palabras: “y, no viendo nada real que satisficiese mi delirio, lo distraje con un mundo ideal que mi imaginación creadora pobló en breve de seres conformes con las aspiraciones de mi corazón.” (trad. en 1948, p. 391). Y es esta misma imaginación libre que promueve la narración la que precisa fijarse para crear nuevas escenas; de esta manera nació la historia de Julia, su prima, y el enamorado preceptor, casi a costas de su autor que, abrumado por sus propias ficciones, decide darles forma para que puedan habitar fuera de su fantasía ${ }^{6}$. Tal como confiesa Rousseau, un escritor auténtico no sólo no debe hacer de su ocupación un medio de vida sino que además debe prácticamente diluirse y plasmar aquello que le trasmiten sus personajes; sólo a través de esta operación puede librarse de su sofocadora presencia. Pero esta entrega del autor no indica una escisión entre razón y sentimiento; por el contrario, en la tranquilidad de su retiro, Rousseau propone una ficción sociable a través de la cual pueden entrelazarse la emotividad y los roces de la vida en comunidad (Cfr. Aranda Torres, 2009, pp. 209216).

Inspirada muy probablemente en la relación y en el intercambio epistolar que tuvo con la señora de Houdetot (Cfr. Rousseau, trad. en 1948, pp. 403 y 424), Rousseau escribió las dos primeras partes de Julia con la intención de conmover al lector, de trasmitirle un tipo de sensibilidad que le “ablande el corazón” (Rousseau, trad. en 1948, p. 401), y con este espíritu comenzó a leer en voz 
alta la novela, primero a su mujer, y luego a la señora de Épinay, que la recibieron con lágrimas y congoja. La Nueva Eloísa fue terminada en 1759 y enviada al rey que ordenó publicarla al año siguiente (Cfr. Rousseau, trad. en 1948, p. 459). La versión final y completa de la obra se hizo pública en 1761, y lo que sin duda fascinó al público francés de mediados del siglo XVIII fue la descripción de los sentimientos, sufrimientos, sueños y valoraciones de los personajes que despliega Rousseau en esta novela. Y es precisamente la expresión de este tipo particular de sensibilidad lo que podemos llamar romanticismo, que si bien tuvo su florecimiento a finales de siglo, posee su antecedente previo en la Julia de Rousseau, ya que en ella la fantasía no es tomada como algo falso o quimérico sino que permite el despliegue de la interioridad de los interlocutores en situaciones tan comunes y complejas como son el matrimonio, la enseñanza y el vínculo con la familia paterna (Cfr. Praz, 1969, pp. 30-31).

La nueva Eloísa recibió el aplauso del público mucho antes de salir de la prensa (Cfr. Rousseau, trad. en 1948, p. 499), y los lectores no repararon en las cartas en las que se realiza una defensa de la muerte voluntaria. Teniendo como centro la reflexión y la crítica de las instituciones del matrimonio, la familia y la educación de pupilos, el tema del suicidio presente en la novela pasó prácticamente desapercibido. Rousseau incluso se sorprendió de que esta obra fuera alabada y el Emilio repudiada y prohibida, aun cuando “Todo lo que hay de atrevido en El contrato social se hallaba ya en el Discurso sobre la desigualdad; todo lo que hay de atrevido en el Emilio se hallaba igualmente en la Julia.” (Rousseau, trad. en 1948, p. 372). Así y todo, hubo quienes se sintieron atacados por los preceptos morales vertidos por Rousseau en su relato epistolar. La lectura de sus páginas indignó especialmente a algunos miembros de la corte que en la ficción eran considerados moralmente inferiores a otras personas comunes ${ }^{7}$, pero nadie levantó una queja sobre el tratamiento del tema del suicidio. Quizás este tipo de inclusiones en contra de la corte -censuradas en algunas oportunidades- fueron generando, de a poco, el tempestuoso clima con que sería recibido el Emilio.

En el caso de la publicación de Sobre el suicidio de Hume en 1783, fue sin dudas su editor quien advirtió el interés que podrían despertar en el público inglés las cartas XXI y XXII de La nueva Eloísa acerca de la muerte voluntaria $\underline{\underline{8}}$. El escrito tuvo excelentes ventas y gran parte de la agitación que provocó puede entenderse por el contexto en el que tuvo distribución. En Inglaterra, una persona que cometía suicidio durante el siglo XVI y comienzos del XVII, era considerada una asesina, se la juzgaba luego de cometer el crimen y, si se la declaraba en sus sanos cabales, era duramente castigada. Su cuerpo se enterraba bocabajo en la vía pública, o en un cruce de caminos, atravesado por una vara de madera para que su espíritu permaneciera inmóvil; no se ofrecía ningún sacramento religioso oficial y, algo que es aún más llamativo, sus pertenencias eran confiscadas por la corona. Las leyes en contra del suicidio no fueron modificadas hasta entrado el siglo diecinueve y, durante la segunda década de ese período, se produjeron los últimos ritos de execración del cuerpo de los suicidas (Cfr. MacDonald, 1986, p. 93). Al mismo tiempo, a mediados del siglo XVIII, la cantidad de suicidios era un problema que afectaba principalmente a Inglaterra y el tema suscitaba una gran preocupación entre intelectuales, juristas y médicos ingleses (Cfr. MacDonald, 1989, pp. 69-91). Así, en los países europeos continentales se comenzó a hablar de la melancolía como el mal inglés, y el mismo término suicidio se difundió primero en Inglaterra y luego en Francia y España (Cfr. Cohen Agrest, 2010, p.73). 
En el contexto antes descrito, Hume se abstuvo de publicar en 1756 los ensayos Sobre el suicidio y Sobre la inmortalidad del alma. Cierto es que, a partir de la edición de 1783, las reseñas que aparecieron de los dos ensayos póstumos no fueron muy propicias. En diciembre de ese mismo año, The Critical Review, que hasta entonces había manifestado su satisfacción en relación con la letra del filósofo, expresó su descontento (Cfr. Fieser, 1996, p. 650). En el mismo sentido, The Monthly Review, que siempre había elogiado la prosa del autor en base a su estilo, creatividad y profundidad, incluyendo la controvertida disertación Historia natural de la religión y sus Diálogos sobre la religión natural, no fue tan favorable en sus opiniones acerca de los dos ensayos, a los que desestimó y repudió duramente. Una reseña similar realizó The English Review, aunque sus críticas no fueron tan fuertes como las anteriores acusaciones, reconociendo cierta seriedad y profundidad en los argumentos expuestos por Hume. William Rose, que se presume era quien realizaba las reseñas de los trabajos del filósofo, escribió en The Monthly Review de 1784 respecto de los dos ensayos:

Si algún libertino alcoholizado lanzara este material nauseabundo en presencia de sus compañeros de fiesta, quizás podría excusarse de alguna manera; pero si cualquier hombre propusiera tales doctrinas en compañía de ciudadanos sobrios, hombres de buen sentido y modales decentes, temo que nadie lo creería merecedor de una respuesta seria, sino que lo escucharían con silencioso desprecio. (citado Citado en Fieser,1996, p. 649, la traducción es nuestra).

Así, a primera vista, si nos guiáramos por la recepción de los escritos de Hume y Rousseau acerca del suicidio, podríamos pensar que las opiniones allí expuestas difieren de manera sustantiva. Pero en lo que sigue veremos cómo, a pesar de haber tenido una aceptación tan disímil, ambos textos coinciden en sus líneas fundamentales. Seguramente el tratamiento de la muerte voluntaria presente en Julia no alarmó en lo más mínimo a la crítica de los salones franceses porque efectivamente en estos círculos no constituía -como sí en Inglaterra- una preocupación pública.

\section{Los argumentos en contra de la condena del suicidio}

Las tres cuartas partes del ensayo Sobre el suicidio están dedicadas a mostrar cómo la interrupción voluntaria de la vida no va en contra de las obligaciones que tenemos respecto de nuestro Creador (Cfr. Holden, 2005, pp. 189-210). La estrategia del filósofo escéptico es hacer ver que, de existir una providencia, ésta esta gobierna el mundo a través de leyes naturales que rigen las modificaciones de la materia. La vida humana, como la del resto de los seres vivos, está gobernada por normas semejantes a las de la materia y el movimiento, que involucran la existencia de capacidades corporales y mentales, de afecciones, de memoria y juicio, a partir de los cuales es posible dirigir el curso de la vida. El argumento central de Hume consiste en sostener que, si el universo posee un rector, este ha dejado librada la vida de los humanos a la misma suerte -o a las mismas leyes- que al resto de los seres sensitivos. Así, el suicidio sería condenable sólo si fuera en contra de las leyes de la naturaleza, y no ya de la Providencia divina, dado que esta -de existirgobierna el universo a través de dichas regularidades. Si se evidencia cierta armonía en el universo, esta es fruto de la interacción entre los seres sensitivos y el mundo material, y las acciones deliberadas de los seres humanos forman parte del orden que observamos en la naturaleza. 
Las facultades de los seres humanos y de todos los demás animales se encuentran limitadas y orientadas por la naturaleza y las cualidades de los cuerpos circundantes, y la acción de todos los animales altera incesantemente las modificaciones y el comportamiento de estos cuerpos. Los ríos detienen el paso del hombre sobre la superficie de la tierra. Pero, cuando se encauzan debidamente, prestan su fuerza para mover máquinas que son de utilidad para el hombre. (Hume, trad. en 2011, p. 495)

Así, los seres humanos no contradicen ningún precepto de la naturaleza al utilizar el juicio, la inventiva y la prudencia para procurarse bienestar. Cuando, en determinadas circunstancias y frente a una dolencia irremediable, se opta por la muerte, no se hace otra cosa que utilizar el conocimiento y el ingenio para rechazar el sufrimiento. De esta manera, la postura de Hume es clara respecto de las consecuencias que se siguen de la muerte voluntaria: esta no contradice ninguna ley natural ni divina, ya que sostener esto último implicaría afirmar que las leyes del universo no son dictadas por el Todopoderoso.

Un planteamiento semejante encontramos en la carta XXI de La nueva Eloísa. El preceptor de Julia, que siempre le escribe líneas llenas de lirismo y pasión en las que expresa su amor y las complicaciones de una relación prohibida, le anuncia en este pasaje de la novela a un amigo que desea quitarse la vida. Pero Rousseau no expresa en una incipiente clave romántica los sentimientos del amante no correspondido tal como lo hace en el resto de la obra sino que, por el contrario, propone al lector una serie de argumentos según los cuales la muerte voluntaria no puede ni debe ser condenada. Uno de los razonamientos más contundentes consiste en advertir que el suicidio no contradice ningún dictamen del creador, si es que este gobierna el mundo a través de las leyes naturales. Al igual que Hume, Rousseau afirma que todo ser humano tiene derecho a modificar su vida en busca del bienestar y, cuando la vida misma se transforma en una carga, a darle fin, sin perturbar por ello ninguna máxima de la providencia: “

Cuanto más reflexiono, más me parece que la cuestión se reduce a esta proposición fundamental: buscar el bien propio y huir del mal, mientras no se lesione a un tercero; esta es la ley de la naturaleza.” (Rousseau, trad. en 2007, p. 419).

Tanto para Hume como para Rousseau la naturaleza se presenta como un conjunto de preceptos que gobiernan el mundo natural inanimado y viviente, y los seres humanos dependemos de las leyes de la física y de la alimentación, al igual que el resto de los animales; pero, al mismo tiempo, nuestra especie posee -como característica que la identifica- la capacidad de innovar y, por ende, de transformar las normas de la naturaleza a las que está sujeta. Nuestra vida está, en un punto, completamente regida por las leyes de la materia y del movimiento y, tal como sostiene Hume, "El derrumbamiento de una torre o una infusión venenosa destruye a un hombre lo mismo que a la más inferior criatura. Una inundación barre sin distinción todo aquello a lo que alcanza su furia.” (trad. en 2011, p. 497). Pero los hombres podemos también variar ciertos preceptos naturales debido a que poseemos, según el filósofo, “la autoridad para hacerlo". Ahora bien, ¿en que se funda dicha autoridad? ¿radica ella misma en algún tipo de artificio propio de la especie humana? Y, de ser así, ¿cómo se conjugan naturaleza y artificio? Más adelante analizaremos, a la luz de algunas fuentes estoicas, esta doble presencia de lo natural en los seres humanos -por decirlo de alguna forma- que inquietó sobremanera a muchos filósofos modernos. 
Volvamos ahora al análisis de las obras que nos ocupan. Un segundo argumento común contra la condena del suicidio, que salta a la vista en ambos textos, es la afirmación de que esta acción no atenta contra los deberes sociales. Tanto para Hume como para Rousseau, quien se quita la vida el peor mal que puede provocar a la sociedad es dejar de procurarle un bien. Cuando la propia existencia dispensa sólo pesares a uno mismo e incluso a terceros, el vínculo moral que nos compromete a procurar el bienestar común, desaparece. Así, en Julia leemos que lo único que podría exigírsele al suicida es honrar sus deudas antes de quitarse la vida, pero obligarlo a que la conserve para realizar futuros favores que podría obtener de él la comunidad sería un abuso:

Confieso que hay deberes para con el prójimo que no permiten siempre al hombre disponer de sí mismo; pero, en cambio, ¡cuántos hay que disponen de él! Que un magistrado responsable de la salvación de la patria, que un padre de familia responsable de la subsistencia de sus hijos, que un deudor insolvente que arruinaría a sus acreedores, a todos éstos que se les obligue a seguir cumpliendo con su deber, suceda lo que suceda; que otras tantas relaciones civiles y domésticas fuercen a un hombre infortunado a soportar la desgracia de vivir para evitar una desgracia mayor como es la de ser injusto; pero, ¿estaría permitido, en casos muy diferentes, conservar una vida a expensas de un montón de desgraciados, una vida que no es útil más que a quien no puede morir? (Rousseau, trad. en 2007, p. 423).

De manera similar Hume sostiene, coherentemente con su noción del bien y del mal morales, que nadie está obligado a promover la utilidad común dejando completamente de lado sus intereses personales:

Todas las obligaciones que tenemos de hacer bien a la sociedad parecen implicar reciprocidad. Recibo los beneficios de la sociedad y por tanto debería promover su interés. Pero, una vez que me retiro totalmente de la sociedad, ¿puedo seguir vinculado a ella? Concediendo que nuestras obligaciones de hacer el bien fueran perpetuas, tienen sin duda algunos límites. No estoy obligado a hacer un pequeño bien a la sociedad a costa de causarme un gran daño a mí mismo. ¿Por qué he de prolongar entonces una existencia miserable, por mor de alguna frívola ventaja que quizá pueda el Estado recibir de mí? (Hume, trad. en 2011, p. 500).

Una última similitud que nos interesa señalar entre las apreciaciones de los filósofos es que ambos poseen la misma opinión acerca de quienes condenan la muerte voluntaria: dichas personas suponen, sin más, que la vida humana posee un valor superior al del resto de los seres vivos. Así leemos en el texto de Hume:

¿Se debe a que la vida humana tiene tan gran importancia que supone un atrevimiento para la prudencia humana disponer de ella? Pero, para el universo, la vida de un ser humano no tiene mayor importancia que la de una ostra. Y, si tuviese una importancia tan grande, el orden de la naturaleza la ha sometido realmente a la humana prudencia, y nos ha reducido a la necesidad de decidir sobre ella en cada situación. (Hume, trad. en2011, p. 497).

La misma idea se expresa en la carta del preceptor de Julia: 
Nuestra vida no es nada a los ojos de Dios, no es nada a los ojos de la razón, no debe significar nada, tampoco, a nuestros propios ojos; y cuando dejamos nuestro cuerpo, no hacemos sino despojarnos de un incómodo vestido, ¿merece la pena hacer tanto ruido por ello? (Rousseau, trad. en 2007, p. 420).

Quienes sostienen que el valor de la vida de los hombres es supremo desconocen, según los filósofos, que dicha apreciación es típicamente humana y que la naturaleza es más bien indiferente respecto del destino de nuestra especie.

Tal como ya señalamos, es llamativo que las dos obras que nos ocupan, y que tuvieron una recepción tan disímil, compartan las mismas críticas a la condena del suicidio. Como indicamos anteriormente, Sobre el suicidio fue enviado a la imprenta en 1756, año en el cual Rousseau comenzó a escribir La nueva Eloísa; pero, de la conflictiva relación entre ambos filósofos, signada por los desencuentros y los malos entendidos $\underline{\underline{9}}$, nada sabemos acerca de si Hume le confió a Rousseau su escrito sobre la muerte voluntaria y menos aún si éste leyó alguna de las copias que circularon clandestinamente de las Cuatro disertaciones antes de escribir la tercera parte de su novela. Lo que intentaremos indagar, entonces, es si Hume y Rousseau han tenido alguna lectura en común que explique la similitud de sus opiniones.

\section{Hume y Rousseau lectores de Montesquieu}

En las Cartas persas, publicadas por primera vez en 1721 de manera anónima y con datos de imprenta falsos, Montesquieu ataca duramente las costumbres y creencias de la sociedad europea de comienzos del siglo XVIII desde la mirada de un extranjero que recorre asombrado las calles de París. Las Cartas persas se imprimieron en Ámsterdam y se convirtieron rápidamente en un éxito editorial, llegando a ser prohibidas por Luis XV, censura motivada sin duda por la constante ridiculización de la corte francesa que en ellas presenta Montesquieu, pero quizás también debida a la crítica más profunda que realiza el filósofo a la moral, la política y la religión occidentales. La carta LXXIV de Usbek a su amigo Ibben, escrita desde París en el año 1715, comienza así:

"En Europa las leyes son inflexibles con los que se suicidan: se les obliga a morir, digamos, por segunda vez. Son indignamente arrastrados por las calles, se les llena de infamia, se confiscan sus bienes. Me parece, Ibben, que estas leyes son muy injustas.” (Montesquieu, trad. en 1992, p. 140).

Estas prácticas de castigo y condena de los suicidas -comunes también en Inglaterra, como ya señalamos anteriormente- aparecen como aberrantes a los ojos de un persa. Y esta es, precisamente, la primera estrategia del autor frente a un tema tan sensible y complejo como es la valoración de la muerte voluntaria: presentar, en dos líneas, la opinión que tendría de las costumbres de París un observador externo. Así el impacto en el lector es, a través de este rodeo, directo: otras culturas repudian, sin más, los hábitos europeos. El segundo paso que da Montesquieu es comenzar a desarrollar los argumentos por los cuales el suicidio no debería ser condenado y, tal como veremos a continuación, las opiniones vertidas en las Cartas Persas son muy similares a las planteadas por Hume y Rousseau.

Montesquieu hace notar cómo no se trasgrede ninguna ley natural, ni tampoco divina, al terminar 
con la propia vida:

¿Altero el orden de la Providencia cuando cambio la estructura de la materia y convierto en cuadrado una esfera que las primeras leyes del movimiento, es decir, las leyes de la creación y la conservación, habían hecho redonda? No, sin duda no hago más que ejercer el derecho que se me ha conferido; y en este sentido puedo alterar a mi gusto toda la naturaleza sin que pueda decirse que me opongo a la Providencia. (Trad. en 1992, p. 141).

Montesquieu sostiene, de igual manera, que la muerte voluntaria no contradice los deberes que tenemos para con la sociedad, casi con las mismas palabras que lo dice Hume: "Estoy obligado a respetar las leyes, cuando vivo bajo las leyes; pero si no, ¿pueden retenerme aún?” (trad. en 1992, p. 141). También es él quien presenta la idea de que la condena al suicidio se debe a una apreciación distorsionada del valor de la vida humana en relación con el resto del universo:

Nos imaginamos que la aniquilación de un ser tan perfecto degradaría toda la naturaleza y no concebimos que un hombre más o menos en el mundo -qué digo- todos los hombres juntos, cien millones de tierras como la nuestra no son más que un sutil y tenue átomo del que Dios no se preocupa más que a causa de la amplitud de su conocimiento. (Montesquieu, trad. en 1992, p. 142).

De esta manera podemos ver cómo los tres escritos sobre la muerte voluntaria pertenecientes al siglo XVIII que hemos analizado comparten los principales argumentos en contra de la condena del suicidio. Sabemos que Hume leyó las Cartas persas $\underline{10}$ y seguramente lo hizo también Rousseau ${ }^{11}$; es muy probable, entonces, que la similitud de sus reflexiones se deba a esta fuente común. Al mismo tiempo, el estilo en el cual está presentado el tema es semejante: Hume escribe su ensayo en forma de discusión entre un interlocutor que condena el suicidio y él mismo como autor que responde criticando esa postura; Rousseau, por su parte, elige -al igual que Montesquieu- el estilo epistolar y redacta dos cartas entre un potencial suicida y su amigo que le da consejos de cómo proseguir con su vida.

Es interesante señalar, asimismo, que si bien las reflexiones de Usbek dirigidas a sus lejanos conciudadanos en las Cartas persas toman la forma de un intercambio postal, pueden perfectamente ser consideradas meditaciones o confesiones; así, el diálogo que procura ofrecer Montesquieu al lector es aquel que se entabla entre las propias opiniones europeas y aquellas extranjeras. Esto es precisamente lo que le ocurre al mismo Usbek, ya que él modifica su visión del mundo a partir de lo vivido, de las nuevas experiencias en Occidente, antes que a través de las respuestas de Ibben; de igual manera, se espera que el lector revea sus propias prácticas cotidianas luego de conocer la mirada externa que ofrece de ellas un persa. En el caso de Hume y Rousseau, tal como veremos más adelante, la escritura dialogada no está dirigida a criticar los hábitos y las leyes de Europa, sino que se centra en las propias convicciones de quien medita acerca de si es conveniente o no ponerle fin a su vida y, por eso mismo, está íntimamente unida a la temática elegida, en la cual no es posible -ni deseable- arribar a conclusiones generales. Pero, antes de avanzar en este punto, volvamos nuevamente a los argumentos en contra de la condena al suicidio presentes en las Cartas Persas.

Tal como señala el viajante persa de Montesquieu, en la Europa del siglo XVII y XVIII, pocos 
defendían el derecho a quitarse la vida. Así y todo, varios pensadores se opusieron durante ese período a la condena del suicidio -tanto por parte de la religión como de las leyes civiles- y, al hacerlo, retomaron argumentos de corrientes filosóficas precedentes. Entre ellas, las reflexiones de los filósofos estoicos fueron, sin duda, el punto de referencia común de la mayoría de los escritos modernos a favor de la legítima elección de poner término a la vida. En el caso de Montesquieu, podemos ver que el pensador que más influyó en sus escritos acerca de la muerte voluntaria fue Séneca, de quien poseía varias obras en su biblioteca, tanto en latín como traducidas al francés (Cfr. Bianchi, 2010, p. 190).

En las Epístolas morales a Lucilio encontramos argumentos semejantes a los presentados por Montesquieu. En la carta XIII y LXX Séneca aborda el tema de la cantidad y la calidad de vida que debe procurarse el sabio, afirmando que no es contrario a las leyes de la naturaleza que alguien, considerando que su vida ha perdido todo valor, le dé fin por sus propios medios. Es interesante ver cómo el filósofo estoico hace frente a una vieja idea -Platónica u órfica, tal vez $\frac{12}{2}$ según la cual quien se quita la vida rompe cierto mandato cósmico:

Encontrarás incluso maestros de sabiduría que niegan sea lícito hacer violencia a la propia vida y consideran como pecado que uno se convierta en su propio asesino: hay que aguardar, dicen, el final que la naturaleza determinó. Quien así habla no se da cuenta de que bloquea el camino hacia la libertad. Ninguna solución mejor ha encontrado la ley eterna que la de habernos otorgado una sola entrada en la vida y muchas salidas. (Séneca, trad. en 1986, I, p. 400).

Es relevante destacar que para un estoico una vida feliz es una vida conforme a la naturaleza, no alejada de ella, y es sabio quien la toma como guía: "Mientras tanto, cosa en la que hay acuerdo entre todos los estoicos, me atengo a la naturaleza; la sabiduría consiste en no desviarse de ella y adaptarse a su ley y ejemplo.” (Séneca, trad. en 2001, p. 173). Según Séneca, los seres humanos dan forma a su vida cuando siguen los preceptos naturales, pero los hombres también descubren en sí mismo cierta voluntad -o fuerza, como vimos que la llamaba Hume- que les permite ser, al mismo tiempo, artífices de su propio destino de acuerdo con un criterio. Y este principio o fuerza es para los estoicos la razón o el juicio, capacidad que no puede faltar en la toma de decisiones. Es sabio y feliz, entonces, quien realiza acciones meditadas y pensadas teniendo como fin la aceptación serena de lo que se manifiesta, y dicho modo de actuar no puede nunca contradecir los preceptos que gobiernan el mundo natural. Así lo expresa Séneca:

Y sin la cordura nadie es feliz, y no está cuerdo aquél a quien las cosas por venir resultan apetecibles como si fueran las mejores. Feliz, por tanto, es el dotado de recto juicio; feliz es el que se contenta con lo presente, sea lo que sea, y el que aprecia sus bienes; feliz es aquél a quien la razón recomienda toda su actitud ante sus bienes. (Trad. en 2001, p. 177).

La opinión de Montesquieu, según la cual la muerte voluntaria no contradice ninguna ley natural, es muy probable, entonces, que tenga su origen en las cartas de Séneca $\underline{13}$. Y el autor de las Cartas Persas parece ser también uno de los pocos que retoma, a inicios del siglo XVIII, el pensamiento de los estoicos con un brillo propio del siglo de las luces, en lugar de menospreciarlo equiparándolo al 
rigorismo moral típico de los hábitos monacales. Al subrayar la continuidad que existe entre las leyes de la naturaleza y las leyes positivas, y al hacer notar que las virtudes del político no coinciden -necesariamente- con las del santo, Montesquieu retoma algunas nociones básicas de la moral estoica y las pone a tono con las discusiones de los ilustrados. El estoicismo abre así paso al ideal de la libertad; a partir de sus reflexiones las decisiones de los individuos pueden ser tenidas en cuenta sin que sus acciones sean valoradas únicamente desde el punto de vista de máximas generales (Cfr. Bonacina, 1996, pp. 84-118).

Es interesante señalar que la idea de naturaleza presente en las filosofías de Hume y de Rousseau también es deudora de la tradición estoica, tal como la presenta Montesquieu en su lectura de las obras de Séneca. Para Hume, la naturaleza nos provee de ciertas creencias indispensables para la vida y nos libra de caer en un completo escepticismo $\frac{14}{}$, pero, al mismo tiempo, no toda creencia natural puede considerarse saludable, por lo tanto es posible -y recomendable- que los seres humanos propongan un criterio del bien y del mal morales. La elección acerca de cuándo y cómo es bueno continuar o poner fin a la propia vida es el caso paradigmático en el cual el individuo actúa, evitando el sufrimiento que implicaría seguir las meras leyes de la alimentación y el movimiento. Rousseau, por su parte, siendo un gran crítico de la vida civilizada y de las grandes ciudades, propone por momentos un retiro al mundo natural, al contacto directo con aquello que no ha sido corrompido por los seres humanos, pero es consciente, al mismo tiempo, de que un individuo completamente aislado y solitario -como él mismo lo experimentó-, sería infeliz (Cfr. Todorov, 1985/1987, pp. 13-37). Efectivamente, la Nueva Eloísa puede leerse como el esbozo de una vuelta comunitaria a la vida en los bosques, en la cual su autor conjuga la convivencia de distintos tipos sociales en medio de un escenario pueblerino y sencillo (Cfr. Starobisnki, 1971/1983, pp. 112-140). Cabe indicar, entonces, que entre las corrientes de pensamiento antiguas que influyeron en los pensadores del siglo XVIII, dando lugar a la aceptación de la naturaleza como guía, por un lado, y al distanciamiento respecto de sus leyes, por otro, el estoicismo es central.

Así y todo, no es simple determinar cuáles son las nociones de naturaleza que han predominado en la modernidad. Una de las tendencias principales fue asumir la existencia de un sustrato ordenado que da forma a lo real y permite que sea comprensible y admirable. Clement Rosset llama a esta tendencia ilusión naturalista: un filósofo naturalista es aquel que sostiene que la naturaleza es un principio armónico que opera independientemente de la producción humana, debiendo esta última procurar asemejarse a las leyes naturales (Cfr. Rosset, 1973/1974, pp. 13-34). Según Rosset, muchos pensadores modernos sufrieron la influencia de este espejismo naturalista, es decir, pretendieron despojarse de todo ideal externo rector del destino humano, criticando las ideas de Dios y de una moral revelada, pero aceptaron implícitamente el orden natural como otro principio normativo y dador de sentido a la vida de los seres humanos. La idea de naturaleza en la que dichos pensadores depositaron toda su confianza tuvo, tal como señala Rosset, un efecto tranquilizador, “como la presencia de una madre”. Así y todo, y aunque no queda muy claro cómo podríamos librarnos de este espejismo naturalista de manera radical, lo que sí podemos advertir es que Hume y Rousseau, si bien mantuvieron la dupla natural-artificial -y en ese sentido cayeron dentro de la ilusión-, al dar lugar en sus filosofías al punto de vista estoico respecto de la relación con el mundo de los fenómenos, priorizaron el espacio del juicio y la deliberación humanas en lugar de proponer la aceptación ciega de las bondades de un mundo ordenado. 
La naturaleza posee, para Hume y Rousseau, una fuerza que el hombre no puede desconocer, y los filósofos que especulan como si el hombre no fuera un ser material están errados; pero los seres humanos tampoco son autómatas y pueden, en mayor o menor medida, decidir el rumbo de sus acciones en base a criterios que no se fundan en un orden natural. La pregunta que surge aquí, sin duda, es: ¿de qué tipo de deliberación se trata?, y también, ¿es posible que el individuo conserve su libertad y, al mismo tiempo, sus acciones sean objeto de un juicio o una valoración moral? En el próximo y último apartado intentaremos dar respuesta a estos interrogantes.

\section{Reflexión final: el diálogo y la posibilidad del juicio acerca de lo particular}

A la pregunta inicial de por qué Hume y Rousseau eligieron la forma del diálogo para exponer sus opiniones filosóficas acerca del suicidio, podemos responder que la elección de este estilo es muy probablemente un legado de Montesquieu y, a través de sus lecturas, de Séneca, que prefirió hablar a Lucilio en un tono personal, evitando la enunciación general de normas de vida e intentando adecuar sus consejos al caso particular (Cfr. Veyne, 1993/1995, pp. 246-260). Pero sus reflexiones respecto de la muerte voluntaria comparten algo más, y es que ambos filósofos coinciden en que la no condena del suicidio no implica su aprobación. Efectivamente, en el presente trabajo hemos planteado algunos argumentos que sostienen que quitarse la vida no constituye un acto repudiable sin más; ahora bien, no es fácil determinar en qué momento esta elección sería aconsejable.

En este sentido, podemos ver que en los escritos de Séneca ya aparece el problema de cómo discernir cuál es el momento oportuno para abandonar la vida. En sus Epístolas Morales el autor-

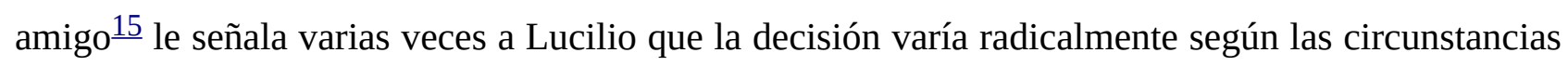
en la que se encuentra la persona; a veces un suicidio puede demostrar un acto de valentía, a veces de cobardía:

Así que no se puede decidir de forma general si hemos de anticiparnos a la muerte o aguardar su venida, en el caso de que una violencia externa nos conmine con ella; existen diversas circunstancias que pueden decidirnos por una u otra alternativa. (Séneca, trad. en 1986, I, p. 399, el destacado es nuestro).

No existe, entonces, una norma general según la cual pueda determinarse si la acción del suicida es reprobable o elogiable. Es por esto que la enumeración y el análisis de casos en los que se aproxima la muerte poseen, a los ojos de un estoico, un fin propedéutico. Así, en el marco de las enseñanzas de Séneca es la observación detenida de las acciones de otros hombres la que permite evidenciar el criterio a seguir.

Rousseau y Hume también incluyen en sus escritos algunos ejemplos de suicidios conocidos, replicando quizás la usanza estoica, pero esta mención no constituye, en el marco de sus filosofías, una guía o modelo a imitar. Lejos de ser el corolario de una vida socialmente virtuosa, la muerte voluntaria es para estos filósofos modernos una acción que no puede ser juzgada a partir de normas generales. El individuo es libre en la elección de su destino, y las leyes civiles y religiosas no pueden imponerse allí donde la misma moral del grupo carece de fundamentos para considerar a una acción como buena o mala. Pero el punto de vista de Hume y Rousseau no supone una idea de sujeto completamente aislado y que posee en sí mismo las respuestas a todos los interrogantes que 
se le presentan. Allí donde las leyes del Estado no se aplican se abre el espacio del diálogo, que es indispensable respecto de aquellas cuestiones que afectan directamente la vida de los individuos, sin caer bajo las reglas de una moral común; y sólo a través de la discusión con otros es posible establecer aquello que es mejor para uno mismo, llegando en estos casos a conclusiones que versan sobre aquello que podría ser de otra manera.

El suicidio, para Hume, al igual que cualquier acción humana, es consecuencia de los motivos para actuar que posee un sujeto empírico que se ve afectado por el clima, la dieta, la edad y las enfermedades y, en este sentido, no es la expresión de una voluntad libre, si por libre entendemos un acto totalmente desvinculado de cualquier motivación o inclinación humana. Los hombres no son dueños absolutos de su vida, que puede ser destruida por causas tan insignificantes como la picadura de un insecto o una caída; pero, entre aquellas acciones que procuran elaborar un proyecto de vida deseable, quizás puedan incluir la posibilidad de ponerle término a sus días. Esta es una acción libre, entonces, sólo porque el dolor, el sufrimiento y la capacidad de superarlos por parte del sujeto son una causa más que lo llevan a elegir una salida. Ahora bien, ¿cómo saber si dicha decisión es recomendable? Así responde Hume en su Ensayo:

Que el suicidio puede a menudo (often) ser coherente con el interés y con nuestra obligación para con nosotros mismos no puede cuestionarlo nadie que conceda que la edad, la enfermedad o la desgracia pueden hacer que la vida sea una carga y se convierta en algo peor que su aniquilamiento. (Hume, trad. en 2011, p. 501).

No es fácil determinar qué entiende el filósofo por aquellas obligaciones que tenemos para con nosotros mismos. Así y todo, en la Sección VI de la Investigación de los principios de la moral, sostiene que aprobamos o condenamos algunos hábitos o cualidades de la gente evaluando si son perjudiciales o favorables para quien los posee $\frac{16}{}$. Cuando examinamos las acciones de alguien no las valoramos solamente en relación a la utilidad que puedan aportar a la sociedad, sino que también analizamos si conducen o no al bienestar de quien las realiza. Entre las tendencias reprobables que menciona Hume encontramos "la indolencia, la negligencia, la falta de orden y de método, la obstinación, el capricho, la precipitación y la credulidad” (Hume, trad. en 2006, p. 115), hábitos que son censurados porque son perjudiciales para quien los practica. Existen, por tanto, ciertas acciones o tendencias a actuar que, sin caer dentro del espacio de la utilidad pública, son objeto de valoración. Ciertamente, el tipo de juicio que tiene en mente Hume cuando habla de aquello que es útil para nosotros mismos es muy diferente de lo que nos parece agradable: la compañía de alguien que posee un carácter melancólico, por ejemplo, puede no ser placentera, pero no por ello merece nuestro reproche. Aquello que es considerado beneficioso o perjudicial para quien actúa dista de ser una apreciación de gusto y supone, antes bien, un tipo de juicio similar al de la aprobación y la censura moral. De todas formas, Hume no es muy claro respecto de cómo debemos entender este nuevo criterio: no especifica si funciona con independencia de aquello que consideramos útil para todos, o si puede reducirse al criterio de utilidad general (aquello que es bueno para el individuo también reporta un beneficio para el grupo), ni tampoco indica cuál de ellos prima (o debería primar) al momento de actuar. Baste por el momento con destacar que, de acuerdo con Hume, alguien que realiza acciones que son beneficiosas para sí mismo también es considerado virtuoso, y que tal juicio valorativo no es espontáneo ni instintivo, sino que surge de una reflexión acerca de 
aquello que creemos útil para otro.

Aquellos deberes que tiene el individuo para consigo mismo, como propone Hume al final de su ensayo Sobre el suicidio antes citado, no son valorados, entonces, desde el punto de vista de la utilidad general, aunque incluyen, sin lugar a dudas, la opinión de personas cercanas cuyos consejos le permiten a quien delibera delinear el rumbo de acción más feliz. Dado que los seres humanos no hemos desarrollado disposiciones idénticas y que las circunstancias en las que nos encontramos varían, aquello que consideramos beneficioso para alguien no está preestablecido, y debido a que el juicio cambia de acuerdo con cada caso no es lícito afirmar, sin más, la aceptación o la prohibición de la muerte voluntaria. Esto implica decir, efectivamente, que hay situaciones en las cuales el suicidio puede llegar a ser considerado ventajoso para alguien y otras en las que no. Quizás precisamente esto es lo que sugiere Hume cuando afirma que "a menudo" -y no siempre- es preferible abandonar la vida cuando ésta se transforma en una carga, en el fragmento final de su ensayo.

Una opinión similar encontramos en la obra de Rousseau. El suicidio es un derecho vedado a los individuos en el marco de las leyes del Estado y, tal como se indica en El contrato social, todo hombre puede poner en riesgo su vida sólo a los fines de resguardarla. Es por esto que el soberano puede exigir a los ciudadanos acciones que, no carentes de peligrosidad, tienen como fin preservar el orden y los derechos de las partes (Cfr. Rousseau, trad. en 1975, pp. 63-65). Una opinión muy diferente encontramos en la Nueva Eloísa; allí las líneas del amigo del preceptor de Julia toman un carácter personal y directo, ausente en El contrato. Al responder la carta en la que el enamorado le confiesa el deseo de terminar con su existencia, el amigo lo reprende abiertamente, pero no porque el joven no vea que el suicidio es un acto prohibido, sino por pensar que al no ser condenable es positivo y deseable:

Pero dejemos de lado las máximas generales, con las que a veces se hace tanto ruido sin que sirvan para nada, ya que en su aplicación siempre hay alguna condición particular que cambia de tal manera el estado de las cosas, que cualquiera puede sentirse dispensado de obedecer las reglas que él mismo dicta a los demás; pues bien se sabe que todo hombre que plantea máximas generales entiende que éstas obligan a todo el mundo, menos a él. Pero, avancemos un poco más. Hablemos de ti. (Rousseau, trad. en 2007, p. 428).

Con esta simple frase: "Hablemos de ti”, el autor pasa a un tipo de reflexión que escapa a las normas generales. El amigo comienza a hablarle al amante no correspondido en clave personal, porque lo conoce, y es esta cercanía al caso particular lo que le permite emitir un juicio, siempre probable, respecto de la bondad de las acciones del individuo para consigo mismo. En las Confesiones podemos ver un ejercicio similar: la identidad de quien escribe se construye en relación con otros y a través de un proceso de autoinspección que se comparte también con el lector.

Lo novedoso en los escritos de Hume y Rousseau acerca del suicidio, que no aparece en las cartas de Séneca ni en la mirada del extranjero persa de Montesquieu, es precisamente el intento de delinear la posibilidad de un juicio (moral) respecto de temas que atañen directamente a la libertad y a la felicidad del sujeto. Aquellos actos que la moral común no prohíbe bajo reglas universales no siempre conducen al bienestar de los individuos; por el contrario, la felicidad personal se construye 
con juicios particulares que incluyen la conversación con otros. Conscientes del abandono de natura y de la generalidad de las leyes del Estado, la intención de ambos filósofos quizás haya sido, entonces, proponer a través de la escritura un espacio de reflexión común que permita al lector preguntarse por aquello que es mejor para su vida.

\section{Notas}

1 T'acqueta omai. Dispera

L'ultima volta. Al gener nostro il fato

Non don ò che il morire. Omai disprezza

Te, la natura, il brutto

Poter che, ascoso, a comun danno impera

E l'infinita vanit à del tutto.

Leopardi, G. (1831) [trad. 2012, J. L. Bernal]. En Cantos (p. 23) . México: UNAM.

$\underline{2}$ Una primera versión de este trabajo fue presentado en las III Jornadas de Filosofía Moderna, UNMP.

$\underline{3}$ Esto ocurre con algunos ensayos y novelas epistolares de la modernidad, y de manera aún más evidente en las autobiografías. En este género -típicamente moderno- difícilmente se pueda distinguir con claridad entre ficción y verdad; parece más bien que las autobiografías se despliegan en un espacio fronterizo entre la veracidad y la imaginación creativa; y la tarea de determinar en qué medida la ficción afecta un género literario es también un problema filosófico. Cfr. Pozuelo Yvancos (2006, pp. 15-69).

4 La recuperación fragmentada de la obra filosófica de varios autores modernos que ha tenido lugar durante la primera mitad del siglo XX es evidente respecto de la producción de David Hume. En relación con sus textos se realizó una primera distinción entre sus escritos históricos y filosóficos y, respecto de estos últimos, se estableció que los más importantes eran las dos Investigaciones y el Tratado, quedando los Ensayos desplazados a la categoría de escritos menores.

$\underline{5}$ Cfr. Ruíz Ortega, en Rousseau (trad. en 2007, pp. 26-32).

$\underline{6}$ “Cuando el invierno empezó a sitiarme en casa, quise suspender de nuevo mis ocupaciones caseras; pero me fue imposible. En todas partes veía las dos bellas compañeras, su amigo, sus paseos, el país en el que moraban, objetos creados o embellecidos por ellas en mi imaginación. No estaba un momento sosegado, el delirio no me abandonaba; y, después de innumerables esfuerzos vanos para apartar de mi mente todas esas ficciones, al fin me vi enteramente reducido por ellas, y no pensé más que en poner alguna ilación y orden para componer una especie de novela.” (Rousseau, trad. en 1948, p. 397).

$\underline{7}$ "En alguna parte de esta obra [Julia] he dicho que la mujer de un carbonero es más digna de respeto que la querida de un príncipe. Esta frase se me había ocurrido en el calor de la composición sin alusión a nadie, lo juro. Al releer la obra, vi a quién se aplicaría [a Madame Pompadour amante de Luis XV]. [...] no quise quitar esta frase, y me contenté con sustituir la palabra rey, que había 
puesto al principio, por la de príncipe. Este paliativo no pareció al señor Malesherbes [editor] suficiente: él la quitó toda, con un cartón que hizo imprimir expresamente y meter con tanta limpieza como fue posible en el ejemplar de la señora de Pompadour. Ella no ignoró esta sustitución; hubo alguna alma caritativa que se la comunicó. Pero yo no lo supe sino mucho tiempo después cuando empecé a experimentar las consecuencias.” (Rousseau, trad. en 1948, p. 468).

$\underline{8}$ Rousseau, por su parte, quizás tenía en mente a los británicos cuando, a raíz del éxito que tuvo en Francia su novela, comenta: "Por ejemplo, si Julia se hubiese publicado en cierto país, que me callo, estoy seguro de que nadie hubiera concluido su lectura y que habría muerto al nacer.” (Trad. en 1948, p. 500). En las Confesiones no se habla en ningún momento de la recepción inglesa de las obras de su autor, y tal vez el silencio fue la respuesta general que Rousseau tuvo para con el público británico.

9 Los dos filósofos se encontraron recién en 1766, año en el cual Rousseau comenzó su estadía en Inglaterra. Para el complicado vínculo epistolar entre Hume y Rousseau, cfr. Goodman (1991-1992, pp. 171-201).

10 Hume menciona las Cartas persas de Montesquieu en su ensayo De lo populoso de las naciones antiguas. (Cfr. Hume, trad. en 2011, p. 342).

11 Rousseau conocía muy bien la obra de Montesquieu (lo menciona varias veces en el Contrato Social, Libro II cap. VII, L. III c. VIII, L. IV c. III), así y todo, nunca mantuvo correspondencia con él y muy pocas veces hace referencia directa a sus obras.

12 En su obra Fedón o del alma, que recrea el último diálogo entre Sócrates y sus discípulos, Platón sostiene que, dado que los hombres reciben la vida de la divinidad, no es lícito que pongan fecha a su término: "los hombres estamos en una especie de prisión y uno no debe liberarse ni evadirse de ella.” (Trad. en 1987, p. 62b).

13 Hume también cita directamente la epístola XII de Séneca en Sobre el suicidio (Hume, trad. en 2011, p. 498).

14 Para un análisis del problema de la creencia y del escepticismo criticado y adoptado por el propio Hume, cfr. Aguirre (2010, pp. 13-40).

15 Nos permitimos citar las bellas palabras de Paul Veyne: "Cuando alguien se dirige a todos, como en los Tratados, hay que exponer razones, seducir, olvidarse de sí mismo; cuando se escribe una carta a uno solo, elevando el papel de gran amigo y halagado de serlo, se puede dejar ver la convicción que desborda” (1993/1995, p. 248).

16 "Parece evidente que cuando sometemos a examen a una cualidad o hábito, si éste se muestra como algo perjudicial para la persona que lo posee, o la incapacita para el negocio y la acción, instantáneamente lo censuramos y lo clasificamos entre las faltas e imperfecciones de dicha persona.” (Hume, trad. en 2006, p. 115). Este tema también es desarrollado, de manera similar, en el Tratado de la naturaleza humana. (Cfr. Hume trad. en 1998, pp. 587-591, numeración Selby Bigge al margen). 


\section{Bibliografía}

Aguirre, L. (2010). David Hume y su adhesión inconsciente al escepticismo pirrónico. Revista de filosofía y teoría política, 41, 13-40.

Aranda Torres, C. (2009). Sobre Julia, o la nueva Eloísa, de Rousseau. La ficción novelesca como figuración sensible. Daímon, 48, 209-216.

Bianchi, L., (2010). La biblioteca de Montesquieu a la Brède. En F. Crasta (ed.) Biblioteche filosofiche private in età moderna e contemporanea. Firenze: Le Lettere. (Atti del convegno Cagliari, abril 2009)

Bonacina, G. (1996). Filosofia ellenistica e cultura moderna. Torino: Le Lettere.

Cohen Agrest, D. (2010). Por mano propia. Buenos Aires: FCE.

De Olaso, E. (1981). Escepticismo e ilustración: la crisis pirrónica de Hume y Rousseau. Valencia: Oficina Latinoamericana de Investigaciones Jurídicas y Sociales.

Durán, I. (1998). Hume y la tradición autobiográfica. En M. Ardanaz, G. López Sastre, F. Martín, Y. Ruano y J. de Salas (eds.), David Hume: perspectivas sobre su obra (pp. 177-188). Madrid: Editorial Complutense.

Falkenstein, L. (1997). Naturalism, Normativity, and Scepticism in Hume's Account of Belief. Hume Studies. XXIII(1), 29-72.

Fieser, J. (1996). The Eighteenth- Century British Review of Hume's Writings. Journal of the History of Ideas, 57(4), 645-657.

Goodman, D. (1991-1992). The Hume-Rousseau Affair: From Private Querelle to Public Process. Eighteenth-Century Studies, 25(2), 171-201.

Holden, T. (2005). Religion and Moral Prohibition in Hume’s 'Of Suicide'. Hume Studies, 31(2), 189-210.

Hume, D. (1998). Tratado de la naturaleza humana (trad. F. Duque). Madrid: Tecnos.

Hume, D. (2006). Investigación sobre los principios de la moral (trad. C. Mellizo). Madrid: Alianza.

Hume, D. (2011). Ensayos morales, políticos y literarios (trad. C. Martín Ramírez). Madrid: Trotta. Larsen, M. (1998). David Hume: reflexiones sobre el ensayo en el siglo XVIII. En M. Ardanaz, G. López Sastre, F. Martín, Y. Ruano y J. de Salas (eds.), David Hume: perspectivas sobre su obra (pp. 207-224). Madrid: Editorial Complutense.

MacDonald, M. (1986). The Secularization of Suicide in England 1660-1800. Past and Present,111, 50-100.

MacDonald, M. (1989). The Medicalization of Suicide in England: Laymen, Physicians, and Cultural Change, 1500-1870. The Milbank Quarterly, 67(1), 69-91.

Montesquieu. (1992). Cartas persas (trad. M. Rocío Muñoz). México: CNCA. 
Mossner, E. C. (1950). Hume’s 'Four Dissertations:' An Essay in Biography and Bibliography. Modern philology, 48(1), 37-57.

Norton, D. \& Norton, M. (1996). The David Hume library. Edinburgh: National Library of Scotland.

Platón (1987). Fedón o del alma. (trad. C. Eggers Lan). Buenos Aires: Eudeba.

Pozuelo Yvancos, J. M. (2006). De la autobiografía. Barcelona: Crítica.

Praz, M. (1969). La carne, la muerte y el diablo en la literatura romántica (trad. Jorge Cruz,). Caracas: Monte Ávila Editores.

Pulley, R. y Charri, N. (eds.) (2011). Discusiones en torno a la Naturaleza Humana: Homenaje a David Hume. Mar del Plata: UNMP.

Rousseau, J. J. (1948). Las confesiones (trad. R. Urbano). Buenos Aires: Jackson.

Rousseau, J. J. (1975) Contrato social (trad. F. de los Ríos) Madrid: Espasa-Calpe

Rousseau, J. J. (2007). Julia o la nueva Eloísa (trad. P. Ruíz Ortega). Madrid: Akal.

Rosset, C. (1974). La anti-naturaleza: elementos para una filosofía trágica. (trad. F. Calvo Serraller). Madrid: Taurus. Obra publicada originalmente en 1973.

Séneca (1986). Epístolas morales a Lucilio (2 vol.). (trad. I. Roca Meliá). Madrid: Gredos.

Séneca (2001). Diálogos (trad. J. Mariné Isidoro). Barcelona: Gredos.

Starobisnki, J. (1983). Jean-Jacques Rousseau. La transparencia y el obstáculo. (trad. S. Gonzáles Noriega). Madrid: Taurus.

Todorov, T. (1987). Frágil felicidad, un ensayo sobre Rousseau (trad. M. Segura). Barcelona: Gedisa. Obra publicada originalmente en 1985.

Toulmin, S. (2001). Cosmópolis, el trasfondo de la modernidad (trad. B. Moreno Carrillo). Barcelona: Península. Obra publicada originalmente en 1991.

Veyne, P. (1995). Séneca y el estoicismo (trad. M. Utrilla). México: FCE. Obra publicada originalmente en 1993. 